\title{
Genre profiles and genre change. The case of TV news
}

\section{Introduction}

There is a broad consensus in genre studies from the "new rhetoric" as well in the "Textlinguistik" tradition of German linguistics that genre change is linked to social change. ${ }^{1}$ Despite the fact that this relation between genre change and social change is pretty complex, changes on the micro level of genre styles are quite often related directly (and sometimes rather recklessly) to the macro level of national or even global cultures. ${ }^{2}$ In TV news studies, genre styles of single TV news shows are often conveyed as characteristics of an entire national TV news style or even as characteristics of a national populace; sometimes the characteristics of (mostly American) TV news shows are generalized globally insinuating a homogeneous global TV news culture.

The main argument of this article is the assumption that we gain a better understanding of genre change in its relation to social change if we look at an analytic meso-level between the style of single genres on a micro-level and social change on a macro-level and that we can do so by analysing and comparing what I call "genre profiles". The concept of genre profiles does not neglect the necessity for an in-depth look at genre style (on the contrary it relies on it), but it makes visible the contouring of an entire genre 'network'. This again lets us understand the significance of single genres within them and lets us thus get an interpretation basis and

1 I am aware of the differences between the concept of "genre" and "Textsorte" - as well of the differences between the various "schools" that study genre (cf. Bhatia 2004: 10) and differences between various conceptualizations of "Textsorte" (cf. Adamzik 2004: 31-48). But as new works in all those fields see genres or Textsorten as social action, I will conflate the different concepts here and translate "Textsorte" as 'genre'.

2 By style I do not only mean different formulaic aspects like rhetoric figures. I understand style as a socially relevant way of realizing a communicative action (Sandig 2006). So next to rhetoric figures all forms are relevant that can and have to be shaped and thus have the potential to carry meaning by differentiation: Next to lexis and grammar also aspects of content, news narratives, communicative functions and situations created by the genres, materiality and other generic aspects are relevant. In addition, given the multimodality of TV news, I also take into consideration the design of images, colours, proportions etc. 
an understanding of their social value. Compared to the analysis of a single genre, changes in genre profiles are a meso-level phenomenon, have a broader empirical base and can contextualize changes of single genres.

Looking for example at the style of newsreader and anchor items (i. e. stories read from a newsreader or an anchor on camera ${ }^{3}$ ) from the Swiss Tagesschau from different decades and looking at them only would give the impression of quite an extraordinary genre stability. Neglecting the content details, the wording of a newsreader item from 1968 could also be realized in an anchor item from today and vice versa. These wordings stage a maximum of distance to the audience and a maximum of detachment (cf. Luginbühl 2009, 2011) by using the inverted pyramid style ${ }^{4}$ as well as formal language and by abstaining from emotional or evaluating phrasings. This again could be related to a journalistic culture with a low market orientation, as it is not at all oriented towards an audience involvement (and this could be overgeneralized as a feature of European TV news of public broadcast stations or as a consequence of a general detachment of Swiss people and so on).

But if we look at the entire genre profiles (cf. section 4), we get quite a different picture: The items read by a newsreader or an anchor dropped from a share of more than 20 per cent of the show's duration in 1968 to less than 4 per cent in 2005. This is not yet genre death - but it is a very clear sign that the significance of these genres changed. This again can be related to the meaning of this form mentioned before: To stage a detached proclamation of an absolute truth. A look at the genre profiles will show that these two genres have been replaced by (partly new developing) genres with another meaning of the genre form. Like this a social change in the editorial staff regarding crucial norms and values of journalistic culture (a phenomenon on the macro level) can be made evident and plausible by an analysis of genre profiles (meso level) which again is rooted in an analysis of single genre's style (micro level).

Changes in genre profiles can be related to changes of other context factors (like e.g. changes in media technology, media systems, but also changes in language use of other communities etc.). But above all these changes can be related

3 A newsreader restricts himself (there were only men in the Swiss "Tagesschau" and the "CBS Evening News") to reading news from a sheet of paper in a very distanced and formal manner, only rarely looking into the camera. If a newsreader leads-in a story at all, he summarizes the most important facts of the event. An anchor is more of a host, addressing the audience directly, leading it through the show, interviewing correspondents and experts etc.

4 The inverted pyramid style is a metaphor for a style of structuring information in a news text, with the most important information (Who?, What?, When?, Where?, Why?, How?) first, then moving on to less important details and finally to more general or background information. 
to the people using those genres. In order to avoid overgeneralizations, I will use the term "community" here (instead of "nation" or "society"). In my understanding, a community is a group of individuals thinking of themselves as being part of a social category (cf. Tajfel and Turner 1986). This understanding includes communities on very different levels, like social groups interacting which each other on a daily basis (like the staff of a TV news show), they can be ethnic groups, societies of a nation, translocal groups etc. An individual is part of several communities.

I will first elaborate an understanding of genres as cultural artifacts, playing a pivotal role in social change as a crucial mean for adjusting and establishing common norms and values in a community. I will argue that genre change, especially change of genre forms, and cultural change are interdependent (section 2). I will then develop a methodological framework for the analysis of genre profiles (section 3). In the next section the results of the comparative genre profile analysis of the American CBS Evening News and the Swiss Tagesschau are presented along the three analytical perspectives of genre profiles (section 4). Finally, I will discuss the results, relating them to changes in journalistic cultures (section 5). ${ }^{5}$

\section{Genre change and social change}

As mentioned before, changes in the language use of mass media genres are related to a lot of different context factors - other media genres, i. e. the generic context being one of them (cf. Devitt 2004: 91). Several scholars (like Straßner 2001; Muckenhaupt 2000: 41; Mould 1984; Barkin 2003: 28; Schwitalla 1993) have pointed out that TV news genres relied in their first years on genres of movie theatre newsreels and radio news shows. The Swiss Tagesschau for instance consisted entirely of film items (i.e. news footage with an off-voice commenting) in the beginning. This replication of established genres in the first phase of new media seems to be the usual case in genre history (Eckkrammer 2011; Raible 2006; Devitt 2004). These replicated genres then start being varied, which can lead to the emergence of new genres, once a variation becomes stable and is regarded as (and often labeled as) a new genre (Eckkrammer 2011: 194).

Of course these variations of the replicated genres are partly enabled by the new possibilities that the new medium offers. But genre changes are always related to new functions a genre is thought to fulfill within a community. Barnhurst and Nerone (2001) analyse the history of newspaper, and they show how

5 For a more detailled discussion see Luginbühl (2014). 
the form of news "includes the way the medium imagines itself to be and to act. In its physical arrangement, structure, and format, a newspaper reiterates an ideal of itself" (Barnhurst and Nerone 2001: 3). In their analysis they illustrate how changes in cultural configurations can be related to changes in newspaper genres. And they reject rightly what they call "technological determinism" (Barnhurst and Nerone 2001: 8), namely the idea of technological changes as driving force behind genre change; a force that is often assumed in mass media genre studies. A look at TV news shows supports that view of Barnhurst and Nerone: not all technological innovations have been applied right away (the Swiss Tagesschau e.g. could have shown correspondents on scene already in the 1960s, but it started doing so only in the late 1970s); other technological innovations only perfected already realized practices (the teleprompter, for example, perfected the gaze into the camera of the $C B S$ anchors, previously enabled by text boards invisible for the audience).

Of course there are other factors next to generic contexts and technological changes that can have an influence on genre change in TV shows, like media system, media market, target audience, political system, national (or: local / international) orientation of the show, etc. (cf. Luginbühl 2010; Hauser and Luginbühl 2012). It may be impossible to identify the impact of the single factors, but I want to focus on two aspects that seem crucial to me regarding genre change: the meaning of the forms and the norms and values of a community using certain genres.

Although genre change can be influenced by many different factors, these factors usually do not have a direct influence on genres. It is the perception andinterpretation of these factors by the people using a genre that decides whether a genre changes, remains unchanged or falls into desuetude. I therefore see genre change primarily related to new or changing communicative needs. But it is important to see that the meaning of a genre can change due to changes of the genre context, even if the form and function of this genre do not seem to change; language use is not only influenced by external context factors, it is a context factor on its own, influencing genre style, genre choice etc. Language therefore does not only change in media (because of changing technologies, media systems or markets), it also changes through media. This is especially true for mass media. Journalistic communities using and creating genres may be small, but their social impact can be huge. The journalist's language use is influenced by and designed with regard to the language of the audience, at the same time it can serve as a model, influencing for example the way we speak and think about politics, wars, economics, etc., but also influencing our expectations of a trustworthy representation of reality.

I will focus in my analysis on genre forms, which are not simply a carrier of information, but which have a meaning of their own - working perhaps on a more subtle, but maybe therefore in an underestimated, not less powerful way. 
Genres have for a long time been considered as textual attributes, an approach that looks at genre form in isolation of its context. Mittell called it the “'textualist assumption"” (Mittell 2004: 172), Devitt (2009: 28) speaks of "formalism". With that assumption came the conceptualization of genres as constituting themselves as a category through common features. But like all categories genres are no intrinsic, "natural" categories, as the works of new genre theory or newer studies of the German "Textlinguistik" point out, they are "social action" (Miller 1984) constituted by discursive practices of human communities, i. e. social practices within a certain culture. As such they rely on, respond to and can also shape social and communicative needs. Once established (e.g. by acquiring a common name, cf. Miller and Shepherd 2004; Eckkrammer 2010: 58), genres do have common traits, which nevertheless can be on very different levels like different aspects of form, content or reader/audience effect. It is at this point that they seem to be stable and "natural" entities.

But genres never are fully stable. As they are realized within a situated activity, as they have to adjust to cultural, situational and individual needs, they have to be flexible to a certain degree. On the other hand genres have to be stable in order to remain recognizable and thus facilitate communication by providing a reliable pattern for fulfilling a communicative need. Genres, as Devitt (2004: 116) puts it, "balance flexibility and stability", and understanding them as form only means neglecting their basis in social, communicative processes. Genres thus facilitate interaction by suggesting conventional and tested, yet flexible patterns of behavior. At the same time communicative genres also construct recurring communicative situations, and given their binding character they structure verbal interaction and thus structure the way social reality is constructed. ${ }^{6}$ Genre studies within the tradition of "new rhetorics" as well as the "Textlinguistik" tradition emphasize this social dimension of genres. Bhatia, Flowerdew, and Johnes (2008), to quote just one example, consider the "use [of texts, M.L.] in social contexts" as a "common commitment" (Bhatia, Flowerdew and Johnes 2008: 3) of different approaches to genre, especially the "multiperspective genre analysis" (Bhatia, Flowerdew and Johnes 2008: 14).

In my analysis I will focus on the cultural context of genres, i. e. a dynamic formation of norms and values of a group that influence (and as we will see are influenced by) genres and genre change. This cultural view is important regarding the interpretation of genre profiles. Discourse communities (be they small like

6 Giddens (1984: 25) called that the "duality of structure"; genres can thus be regarded as "social systems [that M.L.] are both medium and outcome of the practices they recursively organize" (Giddens 1984: 25). 
the community of practice consisting of the staff of a TV news show or big like an entire nation) have to sustain and negotiate their values and norms, their world view (which does not have to be homogeneous, but can be conflicting). ${ }^{7}$ In order to do so they have to balance their norms and values (Linke 2011), which can be perceived in cultural artifacts and are thus related to the symbolic dimension of human action (cf. Goodenough 1957/64; Geertz 1973; Barth 1989). In this understanding of culture, all symbolic action, such as the use of genres, always serve - among other things, of course - the communitarization (and therefore the differentiation) by expressing norms and values, for example in genre choice and genre form. This aspect of expressing is important, as it means that norms and values have to be indicated in a perceivable manner - and this means in a manner that is somehow semiotically materialized in the cultural artifact. The semiosis - and that means the genre form - is thus crucial for cultural processes, as these processes are realized within and at the same time subject to its conditions. Genres as semiotic entities serve communities to negotiate, i. e. establish, stabilize or change their common norms and values. Against the backdrop of these collective norms and values, habitualized and conventionalized forms of language use genres - emerge (cf. Linke 2011). Culture thus can be transmitted and changed in and through communicative exchanges, whereas this process of negotiating relies inevitably on semiotic processes, genres playing a crucial role in it.

Focusing on genre choice and genre style, I will turn my attention to the form of communication, as it is the changing (or sometimes stable) genre style as well as the changing genre profiles that are a collective product and thus most suitable for indicating norms and values. This is especially true for TV news shows (and other mass media genres), where similar contents are presented in quite different forms - changing between shows, nations, languages and phases (cf. Luginbühl 2010). While the content and the main function ("to inform") are comparable, differences in form can be interpreted culturalistically.

The realization of genres as an establishment of collectively acknowledged patterns of language use is always based on stylistic choices, which are not mandatory and therefore could have been made differently; sometimes we can even choose between different genres. What often seems to be - in retrospect - a "logical" consequence of contextual factors are, in fact, stylistic (and therefore generic) decisions, which offer to realize a meaning exceeding the propositional

7 Like genre, culture has for a long time been conceptualized as a static, homogeneous, often nationally defined set of norms and values (cf. Tylor 1871, but already Herder [1772] 1985). This conceptualization changed during the second half of the 20th century towards an understanding of culture as entities of heterogeneous norms and values of different discourse communities. 
content of utterances as "an aspect of substance on a higher level" (Miller 1984: 160) or a form of "secondary significance" (Linke 2011: 30, my translation). The unemotional, inverted pyramid style of the newsreader and anchor items offers for example to realize the impression of detachment, distance and the seemingly unmediated depiction of an absolute, unquestionable truth (instead, for example, closeness to the audience and an almost live reporting of an always developing news story). This again means that (changing) features of genres can be regarded as cultural "positionings", as genres are collective phenomena and style is "meaning made visible" (Fix 2011: 72, my translation). We even have to take into account the possibility that language use can change before the corresponding changes in interpretations and goals become conscious to the language users (cf. Linke 2011).

It is important to note that in this view the genre form is not at all only a carrier, but that it is meaningful and plays an important role in this process of negotiation, which is only possible if norms and values are displayed on a perceivable and thus semiotic level. Common norms and values emerge like this in a process of joint semiotic action (Linke 2009). This importance of form is also acknowledged and emphasized in newer publications of the new genre studies (cf. Devitt 2009).

\section{Genre profiles}

Next to the cultural and situational context, also generic contexts have to be considered for an adequate understanding of genre and especially of genre change: genres are in systematic relationships to other genres. Several concepts have been introduced to grasp this "inter-genre-ality" (Devitt 2009: 44) of genre. Devitt (1991: 339) speaks of "genre sets" consisting of genres produced by a particular professional group, Bazerman (1994: 97) of the more comprehensive "genre systems" referring to interrelated genres interacting in specific settings, Bhatia (2004) speaks of "genre colonies" (Bhatia 2004: 29) consisting of genres with similar function, and on a more abstract level of "disciplinary genres" consisting of all genres of a particular disciplinary or professional domain (Bhatia 2004: 54-55).

In the German “Textlinguistik” concepts like 'genre intertextuality' ("Textsorten-Intertextualität”, Klein 2000) or 'genre networks' (“Textsortennetze” Adamzik 2001, 2004: 94-106) have been established to describe functional, situational, formal and topical relations between genres (cf. Hauser 2012; Adamzik 2011; Janich 2008). Adamzik (2011) firstly distinguishes 'genre fields' (“Textsortenfelder", consisting of topical or functional similar and thus interchangeable genres) and based on Fairclough (2003) 'genre chains' (“Textsortenketten", 
consisting of ordered genres constituting an expectable chain) and secondly integrates fields and chains into 'genre networks' as a more adequate model for genre relations within an interaction system.

All these concepts are based on the observation that genres exist neither individually nor independently. They are linked to other genres that precede or follow them, for example in a production process or within a "super- or macro-genre" like a TV news show (i. e. "a constellation of individually recognized genres”, Bhatia 2004: 57), they are linked to genres with a similar function, which occur in similar situations or which treat the same topic and so on. This means that the significance and value of a genre also depends on the genre system of a community; a system that can be related to the sociological concept of the "communicative budget of a society' ("kommunikativer Haushalt einer Gesellschaft") by Luckmann (1988), focusing the interdependency of genres.

This interdependency is not only observable in a synchronic view, but also in a diachronic perspective: the emergence or change of genres is linked to their generic context (Devitt 2004: 92-101; Gansel 2011; Eckkrammer 2011). If we agree that genres are typified actions for the realization of communicative actions, then the emergence of new genres or the change of existing genres has to be related to situational and/or cultural changes of the community realizing these genres. New situations (or more precisely as new situations interpreted situations) or new norms and values of a community lead to needs that the existing genres cannot fulfill - which is dependent on the actual genre context. And if genres emerge or change, the entire generic context changes, as the significance and value of a single genre depends on this context.

As genres are collectively established, passed on or changed, also genre networks are culturally coined. And if we understand genres and genre networks as key sites for cultural negotiations, then the analysis of genre can grant access to cultural and social change. As mentioned above, the change of single genres over time has been described in many studies, and in some of them (like Bazerman 1994; Bendel 1998; Campbell and Jamieson 1990; Berkenkotter and Huckin 1995; Berkenkotter and Luginbühl 2014; Fleskes 1996; Nickl 2000; Warnke 1996; Yates 1989) the link to social change has been made. What nevertheless remains unsatisfying is the lack of an intermediate analytical level between the micro-level of single genres and the macro-level of the culture of a community (cf. Adamzik 2010: 31). While based on a qualitative analysis of single genres, genre profiles deliver the contour of entire super-genres in an empirically comprehensible manner; changes (or stability) of such contours again can be more plausibly related to social change, as genre profiles analyse a much bigger section of genre activity of the community in question than the analysis of a single genre would. 
With the framework of "genre profiles" I suggest an intermediate analytical level for the description and analysis of changes in genre networks. The concept of "genre profiles" is not directly concerned with the stylistic formation of a genre at a given time within a certain community, but with the contour of genres within a super-genre like a TV news show. The analysis will show in which dominant forms reality and reporting have been and are represented and which changes can be observed and if there really is an 'Americanization' of the Swiss Tagesschau, as it is often said about European TV news shows (Blum 2006; Genz et al. 2001; Thussu 2003).

This outline is analysed under three perspectives: the choice of the genres realized ("genre repertoire"), the relative amount they are realized ("genre frequency") and the way they build genre chains ("genre networks").

\section{Genre repertoire}

As recurring situations usually do not demand for one single genre, we cannot only make a stylistic choice within one genre, but we can also make a choice on the level of genre itself. It is thus important to look at the question of which genres are realized by a certain community (which could be an entire society) at a given time. The term "repertoire" has been introduced by Bakhtin (1986: 60) and then borrowed by Orlikowski and Yates (1994) and Devitt (2004), who defines it as a "set of genres that a group owns, acting through which a group achieves all of its purposes, not just those connected to a particular activity" (Devitt 2004: 57).

If we look at super-genres, we can look at the repertoires within these supergenres, and we can trace the rise of a genre ("genre genesis") in a diachronic perspective as well as "genre death" within a super-genre. As mentioned above, the genre "newsreader item" or "anchor item" have not been realized in the Swiss Tagesschau first format of the 1950s. The following change in genre repertoire in the 1960s can be related to a whole new self-concept of the show with the introduction of a newsreader, seemingly proclaiming an absolute truth.

\section{Genre frequency}

Within a genre profile, it is not only important to identify the genres realized, but also to know something about the quantitative occurrence of a genre. Of course, frequency does not equal importance, but the quantitative significance is important when it comes to changes within a genre profile without a change in the genre repertoire. A frequent genre can become rather insignificant long before its "death" (that's why a look at genre repertoire is not enough) and it can be replaced by another genre (be it a new one or just a more frequently used one).

Frequency can be counted by number of tokens or by their expansion (length in space or time). It might depend on the kind of genre profile to be analysed 
whether the frequency of tokens or their expansion, i.e. their share will allow more insights in the quantitative occurrence. In the case of TV news it seems more adequate to measure frequency in terms of expansion, as this delivers a more appropriate view on the overall appearance of a show. Again the "newsreader item" and the "anchor item" in the Swiss Tagesschau can serve as prime examples: after its emergence in the 1960, it stayed a key genre with a share between 17 and 21 per cent, falling under 10 per cent after 1980 and disappearing in the week analysed of 1999, but re-emerging in the new show's format of 2005 (3.8 per cent share). It will be important to see by which genre it has been replaced and to think about its re-emergence.

\section{Genre networks}

Generic contexts not only are coined by genre repertoires and genre frequencies, but also by intertextual relations between these genres. As mentioned above, these relations can be found on the formal, functional and/or content level, and they can be observed in a diachronic as well as in a synchronic or typological perspective (cf. Luginbühl et al. 2002: 19-25). A lead-in for example is intertextually related synchronically to other stories on the same issue (content), to lead-ins in the same and in other TV news shows (formal) and to the story that it announces (functional). These relations can also be analysed in a diachronic perspective. Regarding genre profiles all usual and regular relations are relevant, especially those within the genre repertoire at stake. It makes for example a difference regarding audience orientation if there is a lead-in by an anchor introducing every major story (which is the case in the CBS Evening News) or if the stories are just strung together without a person in a news studio (which was the case in the 1950s Tagesschau). In my analysis I will focus on "genre linkings" as conventionalized genre chains within the TV news shows.

Figure 1 tries to illustrate very rudimentarily the intermediate level of genre profiles, indicating the increasing level of abstractness by the three levels. In and through the use of genres norms and values are established, passed on and changed; at the same time existing norms and values shape genres. A genre profile as an analytical concept is in between; it is based on observations of single genres, but combines a look at all genres within a certain array (like a super genre) and thus allows an empirical well-grounded interpretation of the cultural meaning and significance of genres. Culture can be related to the norms and values of a very small group of people (the editorial staff of a TV news show, a family, a school class) up to an entire society (cf. the concept of the "communicative budget of a society"); in both cases the norms and values can be heterogeneous, conflicting and dynamic. 


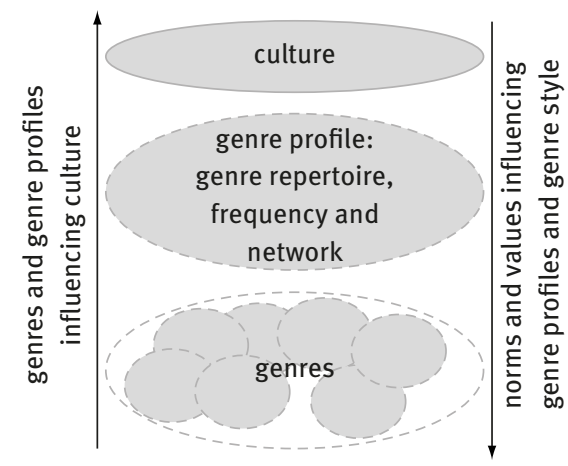

Figure 1: Genre profiles as intermediate level between genres and culture

Defining genre profiles as a combined view of genre repertoires, frequencies and networks, there is an analytical framework looking at genres from three different angles, but always on an intermediate level. And in each angle it is also about making choices. These choices are not on the level of a single genre style, but concern stylistic phenomena on an intermediate level between genres and the communicative budget of a community. The following analysis will show how the genre profiles of the two shows compared changed in very different ways. The significance of these changes, so I would argue, only comes to full light when genre profiles are taken into consideration, next to the change of single genre styles. We will see that the changes of the CBS Evening News are less dramatic and all tend into the same direction (closeness to the audience, immediacy in reporting, authenticity through journalists on scene of the event). In the Swiss Tagesschau, the changes in genre profiles indicate several changes in the "news culture": from a predominantly entertaining show in the 1950s to a detached declaration of a static truth in the 1960s and the 1970s (authenticity through distance), turning to more closeness to the audience and reporting on scene since the 1980s - but with a slight return to more traditional ways of reporting in the newest format since 2005. All these phases come with a specific genre profile.

\section{Genre profiles in TV news shows}

The analytical framework of genre profiles is now applied and discussed in the context of the super-genre of TV news. The analysis will be restricted to the broadcast genres in the shows themselves, neglecting genres relevant during production. Focusing on the published genres the analysis turns to the genres relevant for the audience. 
My corpus allows a contrastive analysis of genre profiles, both in a diachronic and a synchronic way. The corpus consists of seven weeks of the American CBS Evening News from 1968 to 2005 and eight weeks of the Swiss Tagesschau from 1958 to 2005 (there is no archive for the CBS Evening News of the 1950s editions), with one to two weeks per decade. ${ }^{8}$ The CBS Evening News is the main TV news show of the commercial TV network CBS. It has for a long time been the most successful US-American TV network news show, since the early 1990s it has been in the third place of the three big network news shows (behind $A B C$ and $N C B$ ), with a share of nearly six million people each day. ${ }^{9}$ The Swiss Tagesschau is the public TV station's main TV news show. As there is no other national TV news show in German, it is the most successful TV news show in Switzerland; but besides that it is one of the most successful shows of the public Swiss TV station since the 1970s, with about one million people watching daily, which equals to a market share of more than 60 per cent. Both shows claim to report the most important events of the last 24 hours in a balanced, objective way. They both are aired during prime time and last about 20 minutes.

This corpus design allows comparisons on different levels. We can see how the two shows design comparable communicative tasks differently with regard to genres, and we can examine differences between the shows as well as between different phases of the two shows. These comparisons again facilitate the recognition of highly conventionalized forms of reporting as culturally coined artifacts - which is not self-evident, as these conventions are so familiar that their forms often seem to be "natural", the only ones possible.

Although genres are not stable and as they can bend, split up and mix (Bhatia 2004: 73), the analysis of genre repertoires and genre frequencies has to define single genres as selectively and accurately as possible. In most of the cases TV news genres cannot be discerned by their content (a TV news story can report on any event) and only in some cases by their function as the genres often have the same function. A functionally based genre would be the lead-ins, which nevertheless fulfill different other functions (cf. Luginbühl 2009). I thus discerned the genres in a first step based on features of the modes used and the communicative situation established, referring to the ethno-categories of the journalists mentioned in the shows themselves or in journalism handbooks.

Based on criteria like "combination of news footage and language yes or no", “dialogue or monologue”, "narrator on, off or partially on”, “narrator as animator

8 For more details cf. Luginbühl (2014).

9 Cf. Pew Project for Excellence in Journalism 2011, <http://stateofthemedia.org/2012/networknews-the-pace-of-change-accelerates/network-by-the-numbers/> [28 January 2013] 
or identified as author", "narrator within a studio or in the news field" I distinguish the following genres:

- Opening credits, closing credits (genres demarcating TV news shows from the preceding and following shows; usually footage containing some kind of globe and the show's logo, fading to the newsroom)

- Headlines (genres with news footage and the anchor speaking off camera at the beginning of the show, introducing the main stories)

- Greeting, good-bye (genres with the anchor on camera, addressed directly to the audience at the beginning and the end of the show)

- Programme notice, programme preview, story preview (genres with the anchor on camera, announcing an upcoming programme: the next show of the evening [programme notice], a story in the next edition of the TV news show [programme preview], a story in the same edition of the show [story preview])

- Lead-in, lead-out (genres with the anchor on camera, introducing a news story, sometimes completing it by latest developments or some additional information; often with a over-the-shoulder graphic illustrating the news story)

- Anchor item (story read by the anchor on camera; often with a over-the-shoulder graphic illustrating the news story)

- Newsreader item (story read by a newsreader; a person who first and foremost reads news, and does so in a very formal, detached way)

- Anchor voice-over (montage of anchor item, fading to news footage with anchor speaking off camera, i.e. "voice-over”)

- Film item (news footage with voice-over by anchor or newsreader)

- Package (story produced and told by a correspondent, usually containing news footage, parts of interviews or statements, footage of correspondent on scene)

- Statement (sound-bite of a person on camera, not belonging to the editorial staff)

- Interview (interview with another journalist or with a person not belonging to the editorial staff, usually interviewer and interviewee on camera)

- Stand up (story told by a correspondent on camera and on scene, no news footage)

- Commentary (commentary by a member of the editorial staff on camera, in the news studio)

- On screen item (written text, no news footage, no spoken text)

- Special cases (not fitting one of the above characterizations; usually individual cases) 
This methodology is a compromise, allowing an overview of genre profiles, but at the cost of a detailed consideration of genre variation. But as mentioned above, the analysis of genre profiles is not an alternative for qualitative stylistic analysis, but a complement. Nevertheless, unclear cases (like sporadic hybrids) have been counted as "special cases". And in the analysis I will focus on overall trends over decades, not on the precise percentages in the single weeks. Comparing TV news shows, different "formats" can be distinguished regarding their genre profiles; they differ regarding their central and peripheral genres and regarding the way they usually are combined.

\section{Genre repertoires}

Table 1 shows the genres realized in at least one of the two shows since 1958 (Tagesschau) or 1968 (CBS Evening News) and 2005 (the table only includes the English genre names). In the following, I will subsume opening and closing credits, headlines, greeting and goodbye as well as programme notice, programme preview and story preview as "news presentation" genres.

Looking at these repertoires, two observations are striking:

- Both shows realize more or less the same genres, and there are only a few; the genre repertoires are quite narrow. This comes as no surprise: TV news stories have to be produced daily within short time, so the reliance on a few established patterns becomes crucial. The genres realized aim on the one hand at the contact to and orientation for the audience (like greetings, previews or headlines), and to the reporting of events on the other (like anchor items or packages). It is nevertheless interesting to see that there are certain genres that are not realized in either show. This is the case for dialogical genres without clear role allocation, e.g. between studio guests, as they can be found in Japanese TV news shows (cf. Gatzen 2001). These kind of dialogical genres are - compared to the interview - less controllable, which contradicts the image the shows analysed here are trying to communicate, which reveal a core value: to provide a controlled view of the world's events, allowing for chaos and conflict in the news field, but never in the studio.

- There are just a few genres that are realized in only one of the two shows. I will focus on newscaster items and stand ups, as the others (story preview, on screen items) only play a marginal role. In the CBS Evening News all stories are told by identified and visible persons, namely the anchor or a correspondent. Both of them seem very trustworthy: the anchor is not only very familiar to the audience, but he or she also uses quite familiar language and is visually "brought close" to the audience by using close shots. The correspondents are often familiar as well and seem trustworthy as they are shown to be on the scene of the reported event, thus acting as eyewitnesses of these events. 


\begin{tabular}{|c|c|c|c|}
\hline & $C B S$ & Tagesschau & \multirow{19}{*}{$\begin{array}{l}\text { News } \\
\text { presentation } \\
\text { genres }\end{array}$} \\
\hline Opening Credits, Closing Credits & $\checkmark$ & $\checkmark$ & \\
\hline Headlines & $\checkmark$ & $\checkmark$ & \\
\hline Greeting, Goodbye & $\checkmark$ & $\checkmark$ & \\
\hline Programme Notice & $\checkmark$ & $\checkmark$ & \\
\hline Programme Preview & $\checkmark$ & $\checkmark$ & \\
\hline Story Preview & $\checkmark$ & $\varnothing$ & \\
\hline Lead-In, Lead-Out & $\checkmark$ & $\checkmark$ & \\
\hline Anchor Item & $\checkmark$ & $\checkmark$ & \\
\hline Newscaster Item & $\emptyset^{9}$ & $\checkmark$ & \\
\hline Anchor Voice-Over & $\checkmark$ & $\checkmark$ & \\
\hline Film Item & $\checkmark$ & $\checkmark$ & \\
\hline Package & $\checkmark$ & $\checkmark$ & \\
\hline Statement & $\checkmark$ & $\checkmark$ & \\
\hline Interview & $\checkmark$ & $\checkmark$ & \\
\hline Stand Up & $\checkmark$ & $\checkmark$ & \\
\hline Commentary & $\checkmark$ & $\emptyset^{10}$ & \\
\hline On Screen Item & $\checkmark$ & $\varnothing$ & \\
\hline Special cases & $\checkmark$ & $\checkmark$ & \\
\hline
\end{tabular}

Table 1: Genre repertoires of the "CBS Evening News" and the "Tagesschau"

This kind of reporting is brought to an extreme in the "stand up", a story entirely consisting of a correspondent on scene, speaking into the camera - a genre not realized in the Tagesschau. The "newscaster items", not realized in the CBS Evening News, are on the other hand something like the opposite: they are stories read by a very reserved and distanced newsreader, usually reading from a sheet of paper appearing like a "reading machine" (Ballstaedt 1980: 227, my translation). While the genre repertoires are quite similar, we can see slight tendencies regarding central values: trustworthiness through closeness versus trustworthiness through distance. And we also can see that at least certain genres are related to certain ways of reporting, or put differently to certain journalistic cultures of reporting.

10 There were newscaster items in a show of 7 April 1949, archived at the Paley Center for Media, Los Angeles and New York, signature T82:0129.

11 There are commentaries in the Tagesschau, but only on very seldom occasions and there are no instances in my corpus. 


\section{Genre frequencies}

The question of cultural change (or stability) only becomes relevant if we look at genre frequencies (and thus changes in genre repertoires, but also in genre significances). Again: frequency does not equal importance. The greetings at the beginning of TV news shows usually are short, but they are very important regarding the staged relationship to the audience and the entire framing of the show (cf. Luginbühl 2009). But as mentioned above, genres usually come with a certain way of reporting, of addressing the audience, of staging authenticity and of evaluating the reported events. That is why changes in genre frequencies are an important indicator of cultural change. A long-term change in frequency is, as we will see, a reliable indicator of cultural change - even more so if we agree that culture not only shapes genres, but also is shaped by them.

Table 2 shows the genre frequency of the Swiss Tagesschau from 1968 to 2005 , indicating the combined duration of the genres realized in the corresponding week in relation to the show's duration. Opening and closing credits and the year 1958 are not included, as the show then consisted only of film items, strung together without any news presentation (like the newsreels in movie theatres at that time did).

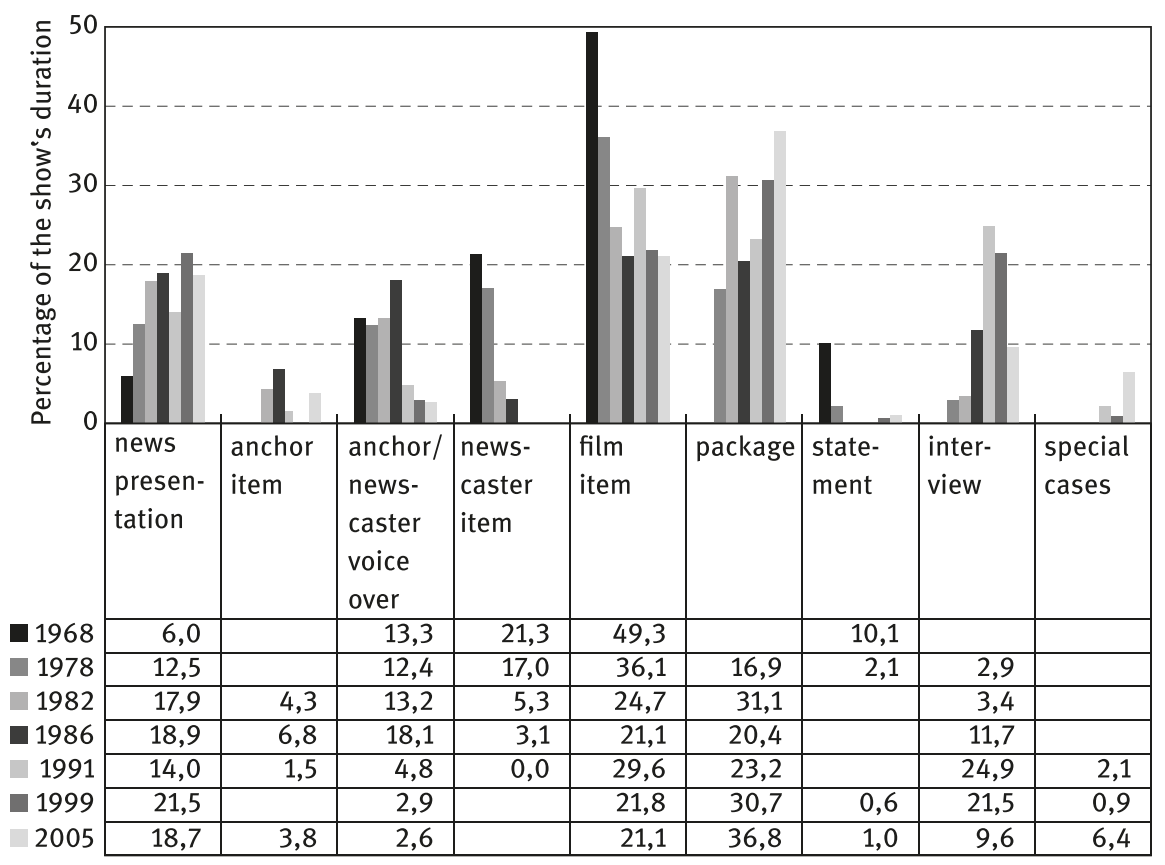

Table 2: Genre frequency of the "Tagesschau" 1968-2005 
As table 2 shows, the genre frequencies changed a lot during the last six decades. It also shows - most importantly - that the genre frequencies do not change in a random manner, but that there are quite obvious trends regarding the most important genres.

The frequency of news presentation genres increased from 0 per cent (in 1958, not in table 2) to about 20 per cent. This is first evidence that the orientation towards the audience changed. And it is an example for a form evolving from culturally peripheral to pivotal (cf. Posner 1991: 56).

Looking at the frequencies of the other genres we not only can see some trends, we can also see that the genres are internally linked, they are in a commercium (cf. Aschenberg 2002: 167), a commerce: some of them expand or emerge newly-made at the cost of certain (not all!) others, which become peripheral or even disappear. The rise of the packages (from 0 per cent to more than 35 per cent) is not at the cost of all, but just of some other genres, especially film items, newscaster items (which disappeared entirely), statements and anchor/newscaster voice-overs (which become more or less insignificant). Other genres gained in significance during that time as well (like all news presenting genres, but also like interviews until the mid-1990s).

The emergence and rise of the package in the Swiss Tagesschau replacing the main share of the film item is part of a paradigm shift. As indicated above, packages (like stand ups) are related to a certain kind of objectivity and prototypically to a certain way of storytelling. In the film items, facts are declared in a distanced, seemingly unchangeable way by an invisible, anonymous news reader, an almost unremarkable camera work and no obvious perspective of a reporting individual. As the film items of the 1960s and 1970s as well as the newscaster items stress a detached, neutral declaration of information, there seems to be a static and absolute truth "out there" "independent of the existence of any perceiver" (Hanitzsch 2007: 376). This kind of reporting can be labeled as totalitarian objectivism; it stages the impression of depicting an unmediated replication of reality. Its market orientation is low, as it comes without dramatic storytelling or emotions; we could speak of an orientation towards citizens (cf. Hanitzsch 2007). ${ }^{12}$

Packages on the other hand promote a different way of reporting: packages tend to mark their medial representation as something always selectively influenced by professional, but individual interpretation, and they do so by showing and naming an individual report, by more clearly showing that the package is a crafted product and by emphasizing the temporary status of the information

12 There were a lot of humourous and entertaining film items in the 1950s; nevertheless the kind of objectivity realized there remains the same. 
given; reporting seems to be a never-ending process of investigation. In addition, packages usually tell a news story in a more or less dramatic and emotional way. This relates to a different kind of objectivism: truth is relative and dynamic, it is conceptualized as something fluid. And of course there is an entirely different relation to the audience in a film item with an anonymous, invisible newsreader and a package with a familiar correspondent on camera. We could call this subjectivist objectivity and market orientation towards consumers (cf. Hanitzsch 2007).

A combined look at genre frequency and genre style delivers an empirically tested way to see the dynamics of packages and film items; it can be complemented by a look at other genres (like the rising share of news presentation, also promoting a more intense relation to the audience).

Table 3 shows the genre frequency of the CBS Evening News, where entirely different genre profiles are realized.

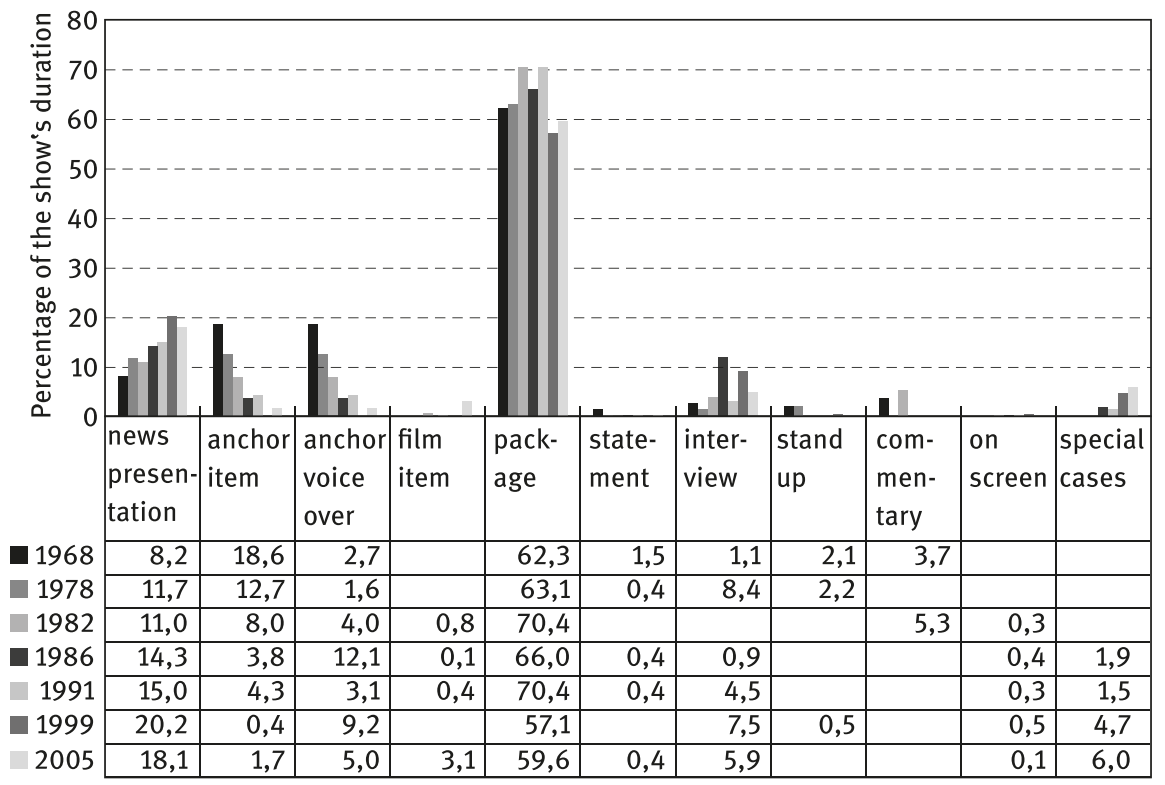

Table 3: Genre frequency of the “CBS Evening News” 1968-2005

The genre frequencies in the CBS Evening News are much more stable compared to the Tagesschau. And since the 1960s the package is the dominant genre, adding up to 60-70 per cent of the show's duration. The changes that can be observed are nevertheless interesting: like in the Swiss Tagesschau the news presenting genres doubled their frequency while anchor items dropped from almost 20 per cent to less than 2 per cent. Also here we can observe that genres are internally linked: 
In weeks, where the share of packages is slightly smaller, this is mostly due to presentation genres, anchor voice-overs and interviews.

It is important to see these charts in comparison, because like this we can see its characteristics in a bigger context. Comparing only TV news shows from public TV stations of European countries or of US American network news would probably not let us recognize the specific features - which not seldom leads to overgeneralizations in TV news studies, assuming that there is a stable and globalized TV news show genre profile.

It becomes obvious that the genre profiles with respect to their frequencies evolve very differently, the Tagesschau profile being much more changing than the CBS Evening News profile. While in the latter the package with an identified, usually visible journalist on scene is at the center of reporting, in the Tagesschau genres with anonymous authors prevail in the 1960s and 1970s; in the film item even the animator remains anonymous in all but his voice. This has changed since the 1980s, where news presentation genres and packages gain significance. Looking at these relations within the genre repertoires we can see how genres are no isolated phenomena. This can serve as an argument that changes in genre profiles are connected to an additional meaning of the genre form - if we assume that reporting on facts of an event could be realized in always the same forms. And this again means that also stability in genre profiles is connected to the meaning of form.

\section{Genre linkings:}

In the case of TV news, the genres are never strung together incidentally, but they are organized on different levels. Be it, that they are strung together in a "news block" because they belong to the same genre (e.g. a "news block" of film items about foreign news), be it, that they treat the same topic and realize different functions regarding the coverage of this topic (like summary in a lead-in, details in a package, reactions in a film item and evaluation in a commentary), be it, that there is a conventionalized syntagmatic order (also containing dependent genres) which could be looked at as "genre linking". Looking at these orders, I distinguish conventionalized orders ("sequential clusters", like lead-in - package - interview with correspondent) and half-conventionalized orders ("serial clusters", like anchor item - lead-in - package - anchor item - anchor item - anchor voice-over - lead out) (for the term “cluster” cf. Püschel 1992). Also by looking at such clusters and their changes we can learn something about genre profiles and the culture they are based upon and which they establish.

Sequential clusters (as conventionalized orders) are an important intermediate dimension regarding genre networks. TV news shows increasingly organize the regular coverage in a sequentialized way, a phenomenon that could be 
described as "sequentialization" of genres within the super-genre of TV news shows. In the CBS Evening News the order "lead-in - package" is already sequentialized in the 1960s: there are no packages without lead-ins, which makes the anchor appear to be an all-knowing mediator of news. In the show of 1949 the film items were broadcast without lead-ins.

In the Swiss Tagesschau film items were for a long time the crucial genre. But they were not sequentialized until the 1980s; until then most film items were broadcast without any lead-in. Similar to the newsreader item, where truth is announced in a distanced way, the not-sequentialized film items contribute to this impression of delivering (or "showing") an unmediated truth. In the 1990s both shows sequentialized the cluster "lead-in - package - interview with correspondent". Here several changes converge that occurred in both shows: the correspondents appear as experts in the interviews (instead of reporters) and the coverage is conversationalized (cf. Fairclough 1995) to a certain degree (instead of a monologue in a stand-up at the end of a package). Over all, this sequentialization also stands for a segmentation of the news coverage. Instead of covering an event in one genre (e.g. a film item) there is a tendency towards pair sequences (lead-in - film item/package) and to multipart sequential clusters. These changes are related to a changing orientation to the audience (more explicit structure of coverage), a changing role of the journalists (from reporter to expert) and a "dialogized" coverage.

Only in cases of extended coverage sequential clusters are replaced by half-conventionalized serial clusters. These are usually based upon sequential clusters, but reduplicate some elements or entire sequential clusters. The serial clusters of the 1960s and 1970s have in both shows been structured according to the inverted pyramid. In a newsreader item or an anchor item the most important facts about the event are given, then they are elaborated in a package (with leadin) and in further newsreader/anchor items, they are contextualized with newsreader/anchor voice-overs or other packages about reactions or consequences and finally they are evaluated in a commentary. These serial clusters can be discontinuous, placing the commentary or a funny kicker about the topic at the end of a show.

Since the mid-1980s (CBS) and the early 1990s (Tagesschau) other kinds of content structures can also be found in serial clusters. There still is a summarizing lead-in at the beginning, but the content of the following genres does not follow the inverted pyramid style, but reports the event from different angles (e.g. packages from war correspondents stationed in different places), giving the impression of an all-embracing, and yet multiperspective and thus balanced coverage. With this content structure comes an explicit organization of clusters 
through the anchors of the show, establishing the news studio as "deictic zero point of enunciation" (Montgomery 2007: 40).

\section{Conclusion}

The two compared TV news shows share more or less the same genre repertoires, but they make different use of these repertoires. As the single genres have different forms of reporting, their forms have different meanings. Some of them stage objectivity by pretending to report without a certain perspective and from a detached point of view, delivering the impression of reporting an absolute, unmediated truth. Others have a visible narrator on scene, who is close to the event and delivers the current state of investigation, which could change any time. A look at the different genres under these aspects does not show real fundamental changes (some Swiss film items of the 1950 s being the only exception). ${ }^{13}$ But a look at the "genre profiles" shows important differences between the two shows and in the case of the Tagesschau far-reaching changes within this show.

In the Swiss Tagesschau, a fundamental change can be observed in the early 1980s. In the 1960s and 1970s genres were realized, that are well suited to present the news in a detached and proclaiming way. The genre profile started to change with new formats introduced after 1980. With these new formats introducing an anchor (instead of a newsreader) came the rise of packages and of news presentation genres - the package making more personal and more investigative reporting easy, as the correspondents deliver the current state of a never-ending process of investigation, her- or himself investigating on scene; the news presentation by an anchor as an optimal genre for "parasocial” communication, realizing patterns of private face-to-face communication in the publicly accessible sphere. At the same time, film items and anchor items become less important, while the newscaster item disappeared altogether. Nevertheless: the change is not unidirectional, as there were very entertaining film items in the 1950 s and a re-emergence of the anchor item in the newest format of 2005. What we can observe is kind of a wave-movement, which makes the label "Americanization" too simple. We also can see that a look at genre profiles always has to be complemented by a look at genre style change.

The genre profiles of the CBS Evening News are much more stable: packages have been and are the pivotal genre, but the share of news presenting genres

13 There are changes regarding other aspects though, like the fastening pace of the genres or the use of more informal style. 
(above all lead-ins) has also grown over time. The journalistic culture seems to be more stable here; a look at changes of single genre styles shows the intensification of certain aspects (like live-reporting, being on scene etc.), but no fundamental changes besides the change of the correspondents from reporters to experts and the dialogization of news reporting.

Regarding genre linkings, a growing sequentialization can be observed. While the packages of the CBS Evening News have conventionally be linked to lead-ins already in the 1960s, the Tagesschau film items have often been broadcast without lead-in - according to the mentioned totalitarian objectivity. In the 1990s, both showed sequentialized chains that include a dialogization of the reporting as well as a change in the journalists' roles, changing from reporters to experts. In addition, a trend towards a multiperspective, fragmented news coverage can be observed, which has intensified the conceptualization of truth as something fluid (subjectivist objectivity).

A combined view of the meaning of genre form and genre profiles allows an empirical, well tested cultural analysis of the genres and generic contexts. Changing repertoires and changing frequencies as well as some changes in genre networks allow us to see the "big picture" of genre change, hinting at trends in cultural change.

In order to avoid overgeneralizations, I suggest - at least in a first step - an analysis in terms of journalistic culture. Comparing the roles of the Tagesschau and the CBS Evening News journalists we can see a diminishing difference in objectivity and market orientation (both core values of journalistic cultures, cf. Hanitzsch 2007) that is centered around the packages and the anchors as hosts. While the CBS Evening News realizes subjectivist objectivity and a consumer-oriented market orientation from the very beginning (and intensifying over time), the Tagesschau started with a totalitarian objectivity and a consumer-oriented market orientation in the 1950s, changing to a citizen-oriented market orientation in the 1960s and 1970s; then changing slowly (but not entirely!) to a more subjectivist objectivity and a more consumer-oriented market orientation since the 1980s. The newest format, though, allows some more traces of a citizen-oriented market orientation to re-emerge.

The changes observed are all based in genre style, in the meaning of genre form, but they also influence the genre profiles of the super-genres. And as genre profiles change, the significance and value of single genres change - given their changing status in the respective profile. Thus we can see that genre profiles are influenced by cultural norms and values of an editorial staff (which again depends on the interpretation of a very complex set of influencing factors), and at the same time genre profiles are one of these influencing factors, establishing cultural norms and values. 
Genre profiles are thus on an intermediate level between the micro-level of genre style and the macro-level of culture, allowing to relate the two levels. The analysis of genre profiles allows the positioning of single texts in the context of parallel textualizations and it lets us recognize different stages of genre network contours. The notion of genre profiles allows the provision of empirical evidence for the significance of genres within super-genres and changes in genre profiles can be related to changes of the non-linguistic context (e.g. changes in the media system, media market or technical equipment) or to cultural change which prefigures itself in language use - or which is realized in it.

\section{References}

Adamzik, Kirsten 2001: Grundfragen einer kontrastiven Textologie. In: Kirsten Adamzik (ed.), Kontrastive Textologie. Untersuchungen am Beispiel deutscher und französischer Sprachund Literaturwissenschaft, 13-48. Tübingen: Narr.

Adamzik, Kirsten 2004: Textlinguistik. Eine einführende Darstellung. Tübingen: Niemeyer.

Adamzik, Kirsten 2010: Texte im Kulturvergleich. Überlegungen zum Problemfeld in Zeiten von Globalisierung und gesellschaftlicher Parzellierung. In: Martin Luginbühl and Stefan Hauser (eds.), MedienTextKultur. Linguistische Beiträge zur kontrastiven Medienanalyse, 17-41. Landau: Verlag Empirische Pädagogik.

Adamzik, Kirsten 2011: Textsortennetze. In: Stephan Habscheid (ed.), Textsorten, Handlungsmuster, Oberflächen. Linguistische Typologien der Kommunikation, 367-386. Berlin/New York: de Gruyter.

Aschenberg, Heidi 2002: Historische Textsortenlinguistik - Beobachtungen und Gedanken. In: Martina Drescher (ed.), Textsorten im romanischen Sprachvergleich, 153-170. Tübingen: Stauffenburg.

Bakhtin, Michail M. 1986: The Problem of Speech Genres. In: Caryl Emerson and Michael Holquist (eds.), Speech Genres \& Other Late Essays. Trans. Vern W. McGee, 60-102. Austin: University of Texas Press.

Ballstaedt, Steffen Peter 1980: Nachrichtensprache und Verstehen. In: Helmut Kreuzer (ed.), Fernsehforschung und Fernsehkritik, 226-241. Göttingen: Vandenhoeck \& Ruprecht.

Barkin, Steve M. 2003: American Television News. The Media Marketplace and the Public Interest. Armonk, N.Y.: M. E. Sharpe.

Barnhurst, Kevin G. and John C. Nerone 2001: The form of news. A history. New York: Guilford.

Barth, Fredrik 1989: Analysis of culture in complex societies. Ethnos 54(3-4): 120-142.

Bazerman, Charles 1994: Systems of genres and the enhancement of social intentions. In: Aviva Freedman and Peter Medway (eds.), Genre and New Rhetoric, 79-101. London: Tayler \& Francis.

Bendel, Sylvia 1998: Werbeanzeigen von 1622-1798. Entstehung und Entwicklung einer Textsorte. Tübingen: Niemeyer.

Berkenkotter, Carol and T.N. Huckin 1995: Genre Knowledge in Disciplinary Communication Cognition/Culture/Power. Hillsdale, NJ: Lawrence Erlbaum Ass.

Berkenkotter, Carol and Martin Luginbühl 2014: Producing genres: Pattern variation and genre development. To appear in: Eva-Maria Jakobs and Daniel Perrin (eds.) (= Handbooks of 
Applied Linguistics 10). pp. 285-304., Handbook of Writing and Text Production. Berlin/ Boston: Mouton de Gruyter.

Bhatia, Vijay K. 2004: Worlds of written discourse. A genre-based view. (Advances in applied linguistics). London/New York: continuum.

Bhatia, Vijay K., John Flowerdew, and Rodney H. Jones 2008: Approaches to discourse analysis. In: Vijay K. Bhatia, John Flowerdew and Rodney H. Jones (eds.), Advances in Discourse Studies, 1-17. London: Routledge.

Blum, Roger 2006: Mediensysteme gehorchen der Politik. Ein Weltatlas nach medienpolitischen Kriterien. Neue Zürcher Zeitung 27. Oktober 2006. http://www.nzz. ch/2006/10/27/em/articleDOOQB.html [31.1.2013].

Campbell, Karlyn Kohrs and Kathleen Hall Jamieson 1990: Deeds Done in Words. Presidential Rhetoric and the Genres of Governance. Chicago: University of Chicago Press.

Devitt, Amy J. 1991: Intertextuality in tax accounting: Generic, referential, and functional. In: Charles Bazerman and James G. Paradis (eds.), Textual dynamics of the professions, 336-380. Madison, WI: University of Wisconsin Press.

Devitt, Amy J. 2004: Writing Genres. Carbondale: Southern Illinois University Press.

Devitt, Amy J. 2009: Re-fusing form in genre study. In: Janet Giltrow, Janet and Dieter Stein (eds.), Genres in the Internet, 27-47. Amsterdam: Benjamins.

Eckkrammer, Eva Martha 2010: Kontrastive Medientextologie und die historische Dimension. Eine theoretisch-methodische Auslotung. In: Martin Luginbühl and Stefan Hauser (eds.), MedienTextKultur. Linguistische Beiträge zur kontrastiven Medienanalyse, 43-65. Landau: Verlag Empirische Pädagogik.

Eckkrammer, Eva Martha 2011: Diachrone Medienanalyse. Zur Analyse multimodaler Vertextungsstrategien in historischer Sicht. In: Hartmut Stöckl and Jan Georg Schneider (eds.), Medientheorien und Multimodalität. Ein TV-Werbespot - Sieben methodische Beschreibungsansätze, 190-215. Köln: Halem.

Fairclough, Norman 1995: Media Discourse. London etc.: Arnold.

Fairclough, Norman 2003: Analysing Discourse. Textual Analysis for Social Research. London: Routledge.

Fix, Ulla 2011: Fraktale Narration. Eine semiotisch-textstilistische Analyse. In: Jan Georg Schneider and Hartmut Stöckl (eds.), Medientheorien und Multimodalität. Ein TV-Werbespot - Sieben methodische Beschreibungsansätze, 70-87. Köln: Halem.

Fleskes, Gabriele 1996 : Untersuchungen zur Textsortengeschichte im 19. Jahrhundert. Am Beispiel der ersten deutschen Eisenbahnen. Tübingen: Niemeyer.

Gansel, Christina 2011: Textsortenlinguistik. Stuttgart: Vandenhoeck \& Ruprecht.

Gatzen, Barbara 2001: Fernsehnachrichten in Japan: Inszenierungsstrategien im interkulturellem Vergleich mit Deutschland. Tübingen: Narr.

Geertz, Clifford 1973: Thick Description: Toward an Interpretive Theory of Culture. In: Clifford Geertz (ed.), The Interpretation of Cultures: Selected Essays, 3-30. New York: Basic Books.

Genz, Andreas, Klaus Schönbach and Holli A. Semetko 2001: “Amerikanisierung”? Politik in den Fernsehnachrichten während der Bundestagswahlkämpfe 1990-1998. In: Hans-Dieter Klingemann and Max Kaase (eds.), Wahlen und Wähler. Analysen aus Anlass der Bundestagswahl 1998, 401-413. Wiesbaden: Westdeutscher Verlag.

Giddens, Anthony 1984: The Constitution of Society. Berkeley: University of California Press. Goodenough, Ward H. 1957/64: Cultural Anthropology and Linguistics. In: Dell H. Hymes (ed.), Language in Culture and Society. A Reader in Linguistics and Anthropology, 36-40. New York: Harper \& Row. 
Hanitzsch, Thomas 2007: Deconstructing Journalism Culture: Towards a universal theory. Communication Theory 17/4: 367-385.

Hauser, Stefan 2012: Textsortennetze im Wandel. Aspekte einer Archäologie der Pressekommunikation. In: Christian Grösslinger, Gudrun Held and Hartmut Stöckl (eds.), Pressetextsorten jenseits der,News', 181-196. Frankfurt a. M.: Peter Lang.

Hauser, Stefan and Martin Luginbühl 2012: What defines news culture? Insights from multifactorial parallel text analysis. In: Stefan Hauser and Martin Luginbühl (eds.), Contrastive Media Analysis. Approaches to linguistc and cultural aspects of mass media communication, 201-218. Amsterdam: Benjamins.

Herder, Johann Gottfried [1772] 1985: Ueber die neuere deutsche Literatur. Fragmente. Im Auftrag der Nationalen Forschungs- und Gedenkstätten der klassischen deutschen Literatur in Weimar, ed. by Regine Otto. Berlin/Weimar: Aufbau-Verlag.

Janich, Nina 2008: Intertextualität und Text(sorten)vernetzung. In: Nina Janich (ed.), Textlinguistik. 15 Einführungen, 177-196. Tübingen: Narr.

Klein, Josef: 2000: Intertextualität, Geltungsmodus, Texthandlungsmuster: Drei vernachlässigte Kategorien der Textsortenforschung - exemplifiziert an politischen und medialen Textsorten. In: Kirsten Adamzik (ed.), Textsorten, Reflexionen und Analysen, 31-44. (Textsorten 1) Tübingen: Stauffenburg.

Linke, Angelika 2009: Stil und Kultur. In: Ulla Fix, Andreas Gardt and Joachim Knape (eds.), Rhetorik und Stilistik, 1131-1144. Berlin/New York: de Gruyter.

Linke, Angelika 2011: Signifikante Muster - Perspektiven einer kulturanalytischen Linguistik. In: Elisabeth Wåghäll Nivre, Brigitte Kaute, Bo Andersson, Barbro Landén and Dessislava Stoeva-Holm (eds.), Begegnungen. Das VIII. Nordisch-Baltische Germanistentreffen in Sigtuna vom 11. bis zum 13. 6. 2009, 23-44. Stockholm: Acta Universitatis Stockholmiensis.

Luckmann, Thomas 1988: Kommunikative Gattungen im kommunikativen „Haushalt“ einer Gesellschaft. In: Gisela Smolka-Koerdt, Peter M. Spangenberg and Dagmar TillmannBartylla (eds.), Der Ursprung von Literatur. Medien, Rollen, Kommunikationssituationen zwischen 1450 und 1650, 279-288. München: Fink.

Luginbühl, Martin 2009: Disclosing and announcing, interpreting and entertaining. A comparative study on the history of TV news presentation in an American and a European national TV news show. In: Charley Rowe and Eva L. Wyss (eds.), Language and New Media: Linguistic, Cultural, and Technological Evolutions, 245-281. Cresskill, NJ: Hampton Press.

Luginbühl, Martin 2010: Sind Textsorten national geprägt? Nachrichtensendungen im Vergleich. In: Martin Luginbühl and Stefan Hauser (eds.), MedienTextKultur. Linguistische Beiträge zur kontrastiven Medienanalyse, 179-207. Landau: Verlag Empirische Pädagogik.

Luginbühl, Martin 2011: Closeness and distance. The changing relationship to the audience in the American TV news show “CBS Evening News" and the Swiss “Tagesschau”. In: Karin Aijmer (ed.), Contrastive Pragmatics, 123-142. Philadelphia/Amsterdam: Benjamins.

Luginbühl, Martin 2014: Medienkultur und Medienlinguistik. Textsortengeschichte(n) der amerikanischen „CBS Evening News“ und der Schweizer Tagesschau (Sprache in Kommunikation und Medien 4). Bern: Peter Lang.

Luginbühl, Martin, Thomas Baumberger, Kathrine Schwab and Harald Burger 2002:

Medientexte zwischen Autor und Publikum. Eine Studie zur Intertextualität in Presse, Radio und Fernsehen. Zürich: Seismo.

Miller, Carolyn R. 1984: Genre as social action. Quarterly Journal of Speech 70: 151-167. 
Miller, Carolyn R. and Dawn Shepherd 2009: Questions for genre theory from the blogosphere. In: Janet Giltrow and Dieter Stein (eds.), Genres in the Internet, 263-290. Amsterdam: Benjamins.

Mittell, Jason 2004: A cultural approach to television genre theory. In: Robert C. Allen and Annette Hill (eds.), The television studies reader, 171-181. London/New York: Routledge.

Montgomery, Martin 2007: The discourse of broadcast news. A linguistic approach. London: Routledge.

Mould, David H. 1984: Historical Trends in the Criticism of the News reel and Television News, 1930-1955. Journal of Popular Film \& Television 12/3: 118-126.

Muckenhaupt, Manfred 2000: Fernsehnachrichten gestern und heute. Tübingen: Narr.

Nickl, Markus 2000: Gebrauchsanleitungen. Ein Beitrag zur Textsortengeschichte seit 1950. Tübingen: Narr.

Orlikowski, Wanda J. and JoAnne Yates 1994: Genre Repertoire: The Structuring of Communicative Practices in Organizations. Administrative Science Quarterly 39: 541-574.

Posner, Roland 1991: Kultur als Zeichensystem. Zur semiotischen Explikation kulturwissenschaftlicher Grundbegriffe. In: Aleida Assmann and Dietrich Harth (eds.), Kultur als Lebenswelt und Monument, 37-74. Frankfurt a. M.: Fischer.

Raible, Wolfgang 2006: Medien-Kulturgeschichte. Mediatisierung als Grundlage unserer kulturellen Entwicklung. Heidelberg: Winter.

Sandig, Barbara 2006: Textstilistik des Deutschen. Berlin/New York: de Gruyter.

Schwitalla, Johannes 1993: Textsortenwandel in den Medien nach 1945 in der Bundesrepublik Deutschland. Ein Überblick. In: Bernd Ulrich Biere and Helmut Henne (eds.), Sprache in den Medien nach 1945, 1-29. Tübingen: Niemeyer.

Straßner, Erich 2001: Von der Korrespondenz zum Hypertext. Zeitungssprache im Wandel. In: Ulrich Breuer and Jarmo Korhonen (eds.), Mediensprache - Medienkritik, 87-102. Frankfurt a. M. etc.: Peter Lang.

Tajfel, Henri and John C. Turner 1986: The social identity theory of inter-group behavior. In: Stephen Worchel and William G. Austin (eds.), Psychology of Intergroup Relations, 7-24. Chicago: Nelson-Hall.

Thussu, Daya Kishan 2003: Live TV and bloodless deaths: War, infotainment and 24/7 news. In: Daya Kishan Thussu and Des Freedman (eds.), War and the media: reporting conflict 24/7, 117-132. London/Thousand Oaks CA: Sage.

Tylor, Edward Burnett 1871: Primitive Culture. Research into the Development of Mythologie, Philosophy, Religion, Language, Art and Custom. London: Murray.

Warnke, Ingo 1996: Historische Dimensionen pragmatischer Textorganisation - Analytische Konzeption und empirische Untersuchung am Beispiel der Intertextualität in spätmittelalterlichen Reichslandfrieden. In: Susanne Michaelis and Doris Tophinke (eds.), Texte - Konstitution, Verarbeitung, Typik, 131-148. München/Newcastle: Lincom Europa.

Yates, JoAnne 1989: Control Through Communication. The Rise of System in American Management. Baltimore: Johns Hopkins University Press. 